\title{
Age at Natural Menopause among Rural and Urban Punjabi Brahmin Females
}

\author{
Maninder Kaur* and Indu Talwar** \\ *Department of Home Science, Kurukshetra University, Kurukshetra, Haryana, India \\ E-mail:maninderkaur_2@yahoo.co.uk \\ **Department of Anthropology, Panjab University, Chandigarh, India \\ E-mail: talwarindu@yahoo.co.in
}

KEYWORDS Menopause. Rural. Urban. Punjabi Brahmin

\begin{abstract}
Present study is an attempt to estimate age at natural menopause among rural and urban Punjabi Brahmin females of Roop Nagar district (Punjab). Cross-sectional data are based on 870 Brahmin females (rural=450, urban=420), ranging in age from 40 to 70 years. Mean and median age at menopause of rural females is $48.22 \pm 2.47$ years and $48.98 \pm 1.12$ years respectively, while among urban females it is $49.30 \pm 2.80$ years and $50.12 \pm 1.15$ years, respectively. These findings indicate that urban Brahmin females experience menopause at a later age as compared to their rural counterparts. The mean age at menopause of rural as well as urban females is found to be earlier than their median ages at menopause. Punjabi Brahmin rural and urban females of the present study exhibit a slightly later age at menopause for females having early menarche.
\end{abstract}

\section{INTRODUCTION}

Reproductive ageing in women is related to the depletion of a fixed number of germ cells within the ovary. Prenatally, almost $50 \%$ of the maximal follicle pool is lost. Thereafter, atresia slows until women reach their early 40's, when total remaining follicle numbers reach a critical threshold. Atresia then becomes rapid once again, and women progress through the menopausal transition until they are left with essentially zero oocytes by a median age of 51.4 years (Santoro 2005). Natural menopause is recognized to have occurred after 12 consecutive months of amenorrhea for which there is other pathological or physiological cause. Menopause may interact with or accelerate event of normal ageing. Early menopause may be a risk factor for earlier mortality from disease related to decreased estrogen levels and may promote increased incidence of osteoporosis, heart disease, diabetes, hypertension, breast cancer, osteoarthritis and autoimmune disease [Mathews et al. 1989; Sowers and La Pietra 1995; Adler 2000). Hence, hormonal changes at menopause are associated with the onset of a number of medical conditions.

Although numerous surveys have been

Address for correspondence:

Dr. Maninder Kaur

Department of Home Science,

Kurukshetra University, Kurukshetra, Haryana, India

E-mail: maninderkaur_2@yahoo.co.uk conducted to estimate age at menopause in different parts of India (Ghosh and Kumari 1973; Singal and Sidhu 1982; Mastana 1996; Talwar and Pande 2004; Sharma et al. 2005), yet there is a dearth of knowledge on this aspect for rural and urban Brahmin females. In view of this, the present study aims to estimate age at natural menopause among rural and urban Punjabi Brahmin females of district Roop Nagar (Punjab)

\section{MATERIAL AND METHODS}

The present study is based on a crosssectional sample of 870 Brahmin (rural $=450$, urban $=420$ ) females, ranging in age from 40 to 70 years. The data were collected in two phases from year 1999 to 2001. In the first phase field work was conducted in rural area and in the second phase from the urban area of district Roop Nagar. Care was taken to include only normal healthy individuals, who were not suffering from any chronic disease or physical deformity. Subjects were selected at random. In determining the age at menarche, the retrospective or recall method was used. While age at menopause was determined by status quo as well as retrospective method. Age in years had been obtained from the date of birth which most of the urban females could recall, whereas in rural female age was ascertained in majority of cases by association with some important events like age at marriage, 
age of the first child, any important festival etc. Women who underwent a hysterectomy prior to their natural menopause or who were taking hormone replacement therapy around the perimenopausal period were excluded from the study.

\section{RESULTS AND DISCUSSION}

The mean age at menopause as calculated by recall method is $48.22 \pm 2.47$ years in rural Brahmin females and $49.30 \pm 2.80$ years in urban Brahmin females. Urban females report later mean age at menopause as compared to their rural counterparts $(\mathrm{t}=6.04, \mathrm{P}<0.01)$. The median age at menopause as calculated by status quo method is $48.98 \pm 1.12$ years in rural population and $50.12 \pm 1.15$ years in urban population. Median age at menopause is found to be significantly higher in urban females than their rural counterparts $(\mathrm{t}=14.86, \mathrm{P}<0.01)$. The results clearly reflect that urban Brahmin females experience mean and median age at menopause at a later age as compared to their rural counterparts. This may be attributed to nutritional differences, less infection, better medical care, and better awareness due to education available to urban females besides reproductive, socio-demographic and certain behavioral influences.

Mean age at menopause of rural as well as urban Brahmin females is found to be earlier than median age at menopause. In rural females, mean age (48.22 years) and median age ( 48.98 years) at menopause differ by 0.76 years, which is statistically significant $(\mathrm{P}<0.01)$. Similarly, in urban females mean age (49.30 years) and median age ( 50.12 years) at menopause differ by 0.82 years, which is also statistically highly significant $(\mathrm{P}<$ 0.01 ). In the previous reports on this issue Brand and Lehert (1978) suggested that the recalled ages at menopause are generally two years earlier than median ages determined by such status quo techniques as Probit analysis. They also report earlier mean age at menopause in thinner women than in heavier women. Sethi et al. (1996) also reported that the recalled age at menopause of Punjabi Khatri working women was almost three years earlier than the median age, while in non working women the recalled age was found to be one and a half years earlier than the median age determined by status quo method. Greer et al. (2003) estimated a lower mean age (48.94 years) than median age at natural menopause (50 years) among Saudi Arabian Women. Ayatollahi et al.
(2005) also recorded an early mean age (48.3 years) than median age (49 years) at natural menopause among women in Shiraz, Islamic Republic of Iran. Whereas contrasting evidences have also been reported by Treloar (1974) and Leidy (1996). They found similarity in median and mean ages at menopause. Poehlman (2002) suggested that natural menopause was associated with reduced energy expenditure during rest and physical activity, an accelerated loss of fat-free mass and increased central adiposity and fasting insulin levels.

To study the regional variation in age at menopause, Brahmin females belonging to rural and urban areas of Roop Nagar district (Punjab) have been compared with the pre-existing data on some of the North Indian populations. Comparison shows that the median as well as the mean age at menopause of urban Punjabi Brahmin females is found to be greater when compared to the mean and median ages at menopause in the previous studies (Ghosh and Kumari1973; Singal and Sidhu 1982; Balgir 1985; Sharma and Hirmani 1985; Sidhu and Sidhu1985; Sidhu 1986; Mastana 1996; Talwar and Pande 2004), except for mean age of Hindu Harijans (Sidhu 1982). Rural Brahmin females also exhibit higher mean and median ages as compared to all other sample females except for Jat Sikh, Punjab (Singal and Sidhu 1982), Hindu Harijan, Punjab (Sidhu 1982), Punjabi Khatri, Chandigarh (Talwar and Pande 2004) and Brahmin, Himachal Pradesh (Sharma and Hirmani 1985).

A number of reports tend to indicate that women living in developing countries including Indonesia, Pakistan, Chile, Peru, and India experience menopause several years earlier (Benjamin 1960; Hauser et al. 1963; Ismael 1994; Yahya and Rehan 2002 ; Samil and Wishnu 1994 ; Morabia et al, 1998; Talwar and Pande 2004) than those in developed countries (Blumel et al. 1988; Wasti et al. 1993; Kato et al. 1998 ). Moreover, the variation in age at menopause of different samples might have its origin in nutritional differences among different populations.

Table1 presents the relationship between the menarcheal age and the mean age at menopause in the rural and urban Punjabi Brahmin females. It exhibits a slightly later age at menopause for females having early menarche in rural as well as urban females. Banerjee and Banerjee (1988) observed a positive correlation of age at menopause with menstrual life. Kim-anh Do et al. (1998) showed that women with late menarche (> 
Table 1: Age at menopause in relation to age at menarche in rural and urban Punjabi Brahmin females

\begin{tabular}{lcc}
\hline \multicolumn{3}{c}{ Rural Punjabi Brahmin Females } \\
Age at Menarche & No. of Women & Mean \pm S.D. \\
\hline 11 years & 4 & $49.05 \pm 1.57$ \\
12 years & 9 & $48.67 \pm 2.06$ \\
13 years & 74 & $48.17 \pm 2.65$ \\
14 years & 143 & $48.08 \pm 2.33$ \\
15 years & 74 & $47.90 \pm 1.88$ \\
16 years & 13 & $47.24 \pm 5.62$ \\
\hline \multicolumn{3}{c}{ Urban Punjabi Brahmin Females } \\
Age at Menarche & No. of Women & Mean \pm S.D. \\
\hline 11 years & 8 & $49.78 \pm 2.73$ \\
12 years & 22 & $49.75 \pm 2.73$ \\
13 years & 77 & $49.41 \pm 3.03$ \\
14 years & 130 & $49.36 \pm 1.98$ \\
15 years & 52 & $49.10 \pm 2.54$ \\
16 years & 4 & $48.77 \pm 4.91$ \\
\hline
\end{tabular}

14 years) had a significantly earlier median age at menopause, compared with women having normal age at menarche (10-14 years). Similiar findings were observed by Sethi et al. (1996), Biela (2002) and Talwar and Pande (2004). Recently, it has been reported that the age at menopause appear to be more sensitive to intrinsic parameters, such as reproductive history of the individuals and age at menarche is more closely related to extrinsic factors such as the living conditions in particular, the energy balance allocated to the individual (Frederic et al. 2001)

The possibility that the age at menopause has risen over the past 100 years has been put forward strongly especially among the European populations. Similarly, a four year increase in the age at menopause over the past 100 years has been suggested (Frommer 1964; Mc Kinlay 1972). Boldsen and Bernara (1990) have also reported slight but significant increase in Danish samples, thereby, confirming a trend towards delayed menopause. The data on Indian studies (Ghosh and Kumari 1973; Sethi et al. 1996 and Wyon 1996) also show a trend towards delayed menopause. Thus, the delay in menopause in the present study may be a trend towards increase in the age at menopause.

With increasing life expectancy, menopause is an increasingly important aspect of women's health (Ayatollahi et al. 2005). In the present research, urban Brahmin females viewed menopause positively. Most of them demonstrate a correct understanding about menopause, related symptoms and about hormone replacement theory. Whereas among rural Brahmin females medication of menopause was negligible and very few rural females have any correct knowledge about menopause and related symptoms. The overall prevalence and intensity of menopausal symptoms were low among urban sample as compared to their rural counterparts. So it is important to impart adequate knowledge about menopausal issues and life in menopause to provide health benefits, quality of life and general well being of elderly females.

\section{REFERENCES}

Adler CN 2000. The relationship of stress to bone loss in postmenopausal women. MAI, 38/06, p.1471.

Ayatollahi SM, Ghaem H , Ayatollahi SA 2005. Sociodemograhic factors and age at natural menopause in Shiraz, Islamic Republic of Iran. East Mediterr Health J, 11(1-2): 146.

Balgir RS 1985. Age at menarche and menopause among Sikligars of Punjab. Journal of Indian Medical Association, 83: 195-197.

Benjamin F 1960.The age of the menarche and of the menopause in white South African women and certain factors influencing these times. S Afr Med J, 34: 316-320.

Biela U 2002. Determinants of the age at natural menopause. Przegl Lek, 59(3): 165-169.

Blumel JE, Cubillos M, Branot A, Munoz L, Ayarza E 1988. Some clinical aspects of menopause. Review of Chile obstetrics and Gynecology, 53: 278-282.

Boldsen J, Bernara J 1990. Distribution of age at menopause in two Danish Samples. Hum Biol, 62(2): 291-300.

Brand PC, Lehert PH 1978. A new way of looking at environmental variables that may affect the age at menopause. Maturitas, 1: 121-32.

Frederic T, Francois R, Eric B, Thierry D, Guegan J 2001. International variability of ages at menarche and menopause: patterns and main determinants. Hum Biol, 73(2): 271-290.

Frommer DJ 1964. Changing age of the menopause. Brit Med J, 2: 349-351.

Ghosh AK, Kumari S 1973. Effect of menarcheal age on fertility. J Ind Anthrop Soc, 8: 165-172.

Greer W, Sandridge AL, Chehabeddine RS 2003. The frequency distribution of age at natural menopause among Saudi Arabian women. Maturitas, 46(4): 26372.

Hauser GA, Remen U, Valaer M, Muller T, Oribi J 1963. Menarche and menopause in Israel. Gynaecologia, 155: $39-47$.

Ismael NN 1994. A study on the menopause in Malaysia. Maturitas, 19: 205-209.

Kar RK, Mahato S 1975. Menarche and menopause among the Singpho women of Arunachal Pradesh. Indian J Phy Anth and Human Genetics, 1: 51-57.

Kato I, Toniolo P, Akhmedkhanov A 1998. A prospective study of factors influencing the onset of natural menopause. J Clinical Epidemiol, 51: 1271-1276.

Kim-Anh Do, Treloar SA, Pandeya N, Purdie D, Green AG, Heath AC, Martin NG, Heath AC, Martin NG 
1998. Predictive factors of age at menopause in a large Australian Twin study. Hum Biol, 70(6): 1073-1091. Leidy LE 1996. Timming of menopause in relation to body size and weight change. Hum Biol, 68(6): 967982

Mastana S 1996. Age at menopause among the Lobanas of North West India. J Hum Ecol, 7(2): 151-153.

Mathews KA, Meilahn E, Kuller LH 1989. Menopause and risk factor for coronary heart disease. New Engl J Med, 321: 641-646.

Mckinlay SM, Jefferys M, Thompson 1972. An investigation of the age at menopause. J Biosoc Sci, 4: 161-173.

Morabia A, Khatchatrian N, Bernstein M 1996. Reproductive characteristic of a population of urban Swiss women. Acta Obstet Gynecol Scand, 75: 838842.

Morabia A, Constanza MC 1998. WHO collaborative study of Neoplasia and Steroid contraceptives. International variability in ages at menarche, fis live birth and menopause. Am I Epidemiol, 148: 1195-1205

Poddar S 1971. Structural Basis and Demogenetic Implications of Local Population Groups of 24 Parganas. Unpublished Ph.D Thesis. Calcutta: University of Calcutta.

Poehlman ET 2002. Menopause, energy expenditure, and body composition. Acta Obstet Gynecol Scand, 81(7): 603-11.

Samil RS, Wishnuwardhani SD 1994. Health of Indonesian women city dwellers of perimenopause age. Maturitas, 19: 191-197.

Santoro N 2005.The menopausal transition. Am J Med, 118(12 suppl 2): 8-13

Sethi HK, Sidhu LS, Singal P 1996. Menopausal age and related factors. In: LS Sidhu, SP Singh (Eds.): Global developments in Human Biology. Ludhiana: USG Publishers and Distributors, pp. 137-151.
Sharma N, Hirmani AB 1985. Estimation of reproductive span of Brahmin and Choudhary females of Kangra (H.P). J Family Wel, 32(1): 231-235.

Sharma N, Vaid S, Manhas A 2005. Age at menopause in two caste groups (Brahmins and Rajputs) from rural areas of Jammu. Anthropologist, 7(2): 111-113.

Sidhu S 1982. A Study of Fertility and Physique in the Scheduled Caste Women of Punjab with Special Reference to Age Changes. Ph.D. thesis (unpublished), Patiala: Punjabi University.

Sidhu S 1986. Reproductive life of some Gujjar women of Punjab. Ind J Phy Anthrop Hum Genet, 12: 225233

Sidhu S, Sidhu LS 1985 Age at menarche and menopause in Sansi females of Punjab. Ind J Phys Anthrop and Hum Genet, 11: 33-37.

Singal P, Sidhu LS 1982. Age at menopause and its association with stature and weight in Jat Sikh and Bania females of Punjab. In: IJS Banasal et al. (Eds.): Human Biology, Recent Advances. New Delhi: Today and Tomorrow's Publishers, pp. 111-118.

Sowers MR, La Pietra MT 1995. Menopause: Its epidemiology and potential association with chronic diseases. Epidemiol Rev, 17: 287-302.

Talwar I, Pande H 2004. Age at menopause among the Khatri females. Journal of Indian Anthropological Society, 39: 91-95.

Treloar AE 1974 Menarche, menopause and intervening fecundability. Hum Biol, 46: 89-107.

Wasti R, Robinson S C, Khan Y, Bavaruddin N 1993. Characteristics of menopause in three groups in Karachi, Pakistan. Maturitas, 16:61-69.

Wyon JB 1966. Differential age at menopause in the rural Punjab (India). Population Index, 32: 328.

Yahya S, Rehan N 2002. Age, pattern and symptoms of menopause among rural women of lahore. $J$ Ayub Med Coll Abbottabad, 14(3): 9-12. 